\title{
Effect of ZnO Addition on the Structure, Microstructure and Dielectric and Piezoelectric Properties of $\mathrm{K}_{0.5} \mathrm{Na}_{0.5} \mathrm{NbO}_{3}$ Ceramics
}

\author{
Leandro Alfredo Ramajo*, Jonathan Taub, Miriam Susana Castro \\ Instituto de Investigaciones en Ciencia y Tecnología de Materiales - INTEMA, CONICET - UNMdP, \\ J. B. Justo 4302, B7608FDQ - Mar del Plata, Argentina
}

Received: September 27, 2013; Revised: February 10, 2014

\begin{abstract}
Microstructure, structure and electrical and dielectric properties of $\mathrm{ZnO}$-doped $\mathrm{K}_{0.5} \mathrm{Na}_{0.5} \mathrm{NbO}_{3}$ $(\mathrm{KNN})$ ceramics were investigated. Powders were obtained by the conventional solid-state method. Samples doped with 0 to $1 \mathrm{~mol} \%$ of $\mathrm{ZnO}$ were sintered at $1125^{\circ} \mathrm{C}$ for $2 \mathrm{~h}$. Through XRD spectra, the perovskite structure was detected, in addition to small peaks corresponding to secondary phases. It was also observed that zinc changed the microstructure and grain size of KNN ceramics. The addition of $0.5 \mathrm{~mol} \%$ of $\mathrm{Zn}^{2+}$ produced a softening effect in the ferroelectric properties of the material, and increased its final density. Conversely, the addition of $1 \mathrm{~mol} \%$ of $\mathrm{Zn}^{2+}$ reduced the sample densification.
\end{abstract}

Keywords: A. Ferroelectrics, B. Solid-state reactions, C. Piezoelectricity

\section{Introduction}

From the view of the sustainable development, considerable attention for environment friendly lead-free piezoelectric ceramics has been paid to $\mathrm{K}_{\mathrm{x}} \mathrm{Na}_{1-\mathrm{x}} \mathrm{NbO}_{3}$-based ceramics $(\mathrm{KNN})$ in recent years ${ }^{1,2}$. Alkaline niobates have shown valuable piezoelectric and electric properties when the compositional ratio is near $\mathrm{x}=0.50$. This composition is reported to show a virtual morphotropic phase boundary where the total polarization is maximized by an increase in oriented domains. Moreover, the orthorhombic crystal structure at room temperature and a high $\mathrm{T}_{\mathrm{C}}$ favor the use of this piezoelectric material for high temperature applications ${ }^{3,4}$. Nevertheless, the dielectric and piezoelectric properties of pure $\mathrm{KNN}$ are relatively low $\left(\mathrm{d}_{33} \sim 90 \mathrm{pC} / \mathrm{N}\right)$ as compared to those achieved with PZT. This makes the replacement of conventional PZT with KNN very difficult ${ }^{5-7}$.

To solve this problem several options have been studied. Hot pressing could improve the final density of these ceramics. Although this technique is able to obtain high densities and better properties compared to conventional air-sintered samples, it needs careful investigation and optimization of sintering parameters to result in reproducible and high quality ceramics ${ }^{8}$. Additionally, it is a more expensive route compared to the conventional sintering process. Then, the study of different additives to obtain KNN with low porosity and good electrical properties by conventional methods is extremely important. In previous published papers we found ${ }^{9}$ that $\mathrm{Ca}^{2+}$ and $\mathrm{Ba}^{2+}$ ions substitute alkaline elements $\left(\mathrm{Na}^{+}\right.$and $\mathrm{K}^{+}$ions) in " $\mathrm{A}$ " sites of the perovskite lattice producing cationic vacancies and consequently "softening" the properties of the ceramic. When dopant concentration is increased, $\mathrm{Na}^{+}$and $\mathrm{K}^{+}$are segregated. Sodium will tend to volatilize and to increase the porosity while the potassium will tend to form a glassy phase. Because of the increase in porosity and secondary

*e-mail: lramajo@fi.mdp.edu.ar phases, properties get deteriorated with the incorporation of high dopant amounts.

Previous works have shown that the addition of zinc generates the formation of a liquid phase during sintering in air. This liquid phase would reduce sintering temperatures, preventing the volatilization of elements such as sodium during this process ${ }^{10,11}$. However, it is also expected that $\mathrm{Zn}^{2+}$ ions $(88 \mathrm{pm})$ replaces niobium ions $\left(\mathrm{Nb}^{5+}, 78 \mathrm{pm}\right)$ of the lattice with the consequent oxygen vacancies generation producing a hardening effect on the ferroelectric properties of the material ${ }^{12}$. Moreover, other authors suggest the possible A-site replacement of $\mathrm{Zn}^{2+}$ ions which provokes the cationic vacancies formation which produces a softening effect on the material properties ${ }^{13}$. Li et al. determined that with adding $0.6 \mathrm{~mol} \%$ of $\mathrm{ZnO}$, the $\mathrm{Zn}^{2+}$ first enters the A-site while higher amounts of $\mathrm{Zn}^{2+}$ substitutes B-site ions when the additive was incorporated in the initial mixture ${ }^{14}$.

Based on these studies, in this work the effect of the $\mathrm{ZnO}$-doping on the structural and microstructural evolution and its influence on the final properties of $\mathrm{K}_{0.5} \mathrm{Na}_{0.5} \mathrm{NbO}_{3}$ based ceramics is presented. Different contents of $\mathrm{Zn}^{2+}$ were analyzed to provide an alternative approach for lead-free materials development.

\section{Experimental}

Lead-free potassium sodium niobate $\mathrm{K}_{0.5} \mathrm{Na}_{0.5} \mathrm{NbO}_{3}$ (KNN) was produced by the conventional solid state reaction method from potassium carbonate (Biopack 99.5\%, Argentina), sodium carbonate (BioPack 99.5\%, Argentina), and niobium oxide (Aldrich $99.9 \%$, USA). Powders with $\mathrm{K}: \mathrm{Na}=1: 1$ were mixed in 2-propanol and milled in a planetary laboratory ball-mill (Fritsch, Pulverisette 5), with zirconium oxide grinding jars and balls, for $6 \mathrm{~h}$ at $1000 \mathrm{rpm}$. Afterwards, the resulting powders were calcined at $900^{\circ} \mathrm{C}$ for $5 \mathrm{~h}$ in air. Then, powders were mixed with zinc oxide 
(Aldrich 99.5\%, USA) using different $\mathrm{Zn}^{2+}$ concentrations $(\mathrm{x}=0,0.5$ and $1 \mathrm{~mol} \%)$ and remilled and dried.

The resulting powders were uniaxially pressed into discs of $6 \mathrm{~mm}$ diameter and $0.5 \mathrm{~mm}$ thick. In order to analyze the influence of zinc addition on KNN-ceramics, all samples were sintered using the same sintering cycle $\left(1,125^{\circ} \mathrm{C}\right.$ for 2 hours in a conventional furnace using $5^{\circ} \mathrm{C} / \mathrm{min}$ heating and cooling rates).

The apparent density was measured by the Archimedes method and the porosity was determined using the theoretical density ${ }^{5}$. The crystalline phases were assessed by X-ray diffraction, using a Philips PW1830 diffractometer running with $\mathrm{CuK} \alpha$ radiation, at $40 \mathrm{kV}$ and $30 \mathrm{~mA}$. Raman spectra were acquired at room temperature with a Renishaw in Via Raman spectrometer by means of the $514 \mathrm{~nm}$ Ar-ion laser line (10 $\mathrm{mW}$ nominal power). The microstructure of the samples was examined by Scanning Electron Microscopy (SEM), using a JEOL JSM-6460LV microscope. Image Pro-Plus Analyzer was used to measure the grain size distribution. The shape of each grain was copied onto a transparent sheet, and then digitized and processed before to be analyzed by the software.

For the electrical measurements, silver electrodes were painted on both faces of the sintered samples. Dielectric properties were measured using a frequency range of $0.10 \mathrm{~Hz}$ to $10 \mathrm{MHz}$, employing both Hioki 3535 and 3522-50 LCR meters. Polarization versus electric field hysteresis loops were obtained in a silicone oil bath at room temperature by applying an electric field of sinusoidal waveform at a frequency of $50 \mathrm{~Hz}$ by means of a modified SawyerTower bridge. For the measurement of the piezoelectric constant, samples were first polarized inside a silicone bath using $2.5 \mathrm{kV} / \mathrm{mm}$ for $30 \mathrm{~min}$ at $150{ }^{\circ} \mathrm{C}$, and finally, the piezoelectric coefficients $d_{33}$ were recorded using a quasistatic piezoelectric $d_{33}$ meter $\left(\right.$ Piezo d $_{33}$ Test System Model: YE2730-Sinocera Inc.).

\section{Results and Discussion}

Figure 1 shows XRD patterns corresponding to KNNbased ceramics doped with different $\mathrm{ZnO}$ amounts ( 0 to $1 \mathrm{~mol} \%)$. The presence of a predominant phase related to $\mathrm{KNN}$ with a main orthorhombic perovskite structure has been detected. Moreover, small peaks associated to the presence of a secondary phase can be assigned to $\mathrm{K}_{4} \mathrm{Nb}_{6} \mathrm{O}_{17}$ (JCPDS76-0977) resulting from slight changes in stoichiometric ratio due to highly volatile alkaline elements during sintering process. Rubio-Marcos et al. studied the effects of $\mathrm{ZnO}$ addition on the structure of a more complex system $\left(\mathrm{K}_{0.44} \mathrm{Na}_{0.52} \mathrm{Li}_{0.04}\right)\left(\mathrm{Nb}_{0.86} \mathrm{Ta}_{0.10} \mathrm{Sb}_{0.04}\right) \mathrm{O}_{3}(\mathrm{KNL}-\mathrm{NTS})^{13}$. They found that the perovskite structure with tetragonal symmetry predominated in all samples. Moreover, samples showed slight evolution of the tetragonal $\left(\begin{array}{lll}0 & 0 & 2\end{array}\right)$ and $\left(\begin{array}{lll}2 & 0 & 0\end{array}\right)$ diffraction peaks with increasing $\mathrm{ZnO}$ content. They attributed this structural evolution to three factors: (i) the incorporation of $\mathrm{Zn}^{2+}$ cations into the perovskite structure, (ii) the existence of a phase polymorphism on KNN-based materials composed of a main tetragonal phase and traces of a residual, low temperature orthorhombic phase and (iii) the presence of a secondary phase. However, in our samples the lattice parameters of KNN ceramics do not change significantly with the addition of $\mathrm{ZnO}$ content, indicating that few $\mathrm{Zn}^{2+}$ ions enter the matrix of the $\mathrm{KNN}$ ceramics. This behavior could be associated with the additive incorporation after the formation of the KNN-phase.

In order to obtain additional information about the structural evolution, Raman spectroscopy analysis were carried out on sintered samples (Figure 2). This technique is a very sensitive tool to study the structural deformations of the ceramic unit cell at a local scale. In the KNN structures, the main vibrations are associated with the $\mathrm{NbO}_{6}{ }^{-}$octahedron $\left(\mathrm{BO}_{6}{ }^{-}\right)^{15}$. Therefore, the deformations are induced by the tilting of octahedral and the cationic displacements ${ }^{16}$. These modifications induce large changes in internal modes associated with $\mathrm{NbO}_{6}{ }^{-}$octahedron resulting in a modification of the Raman spectra ${ }^{17}$. Therefore it can be seen that the Raman spectrum peaks

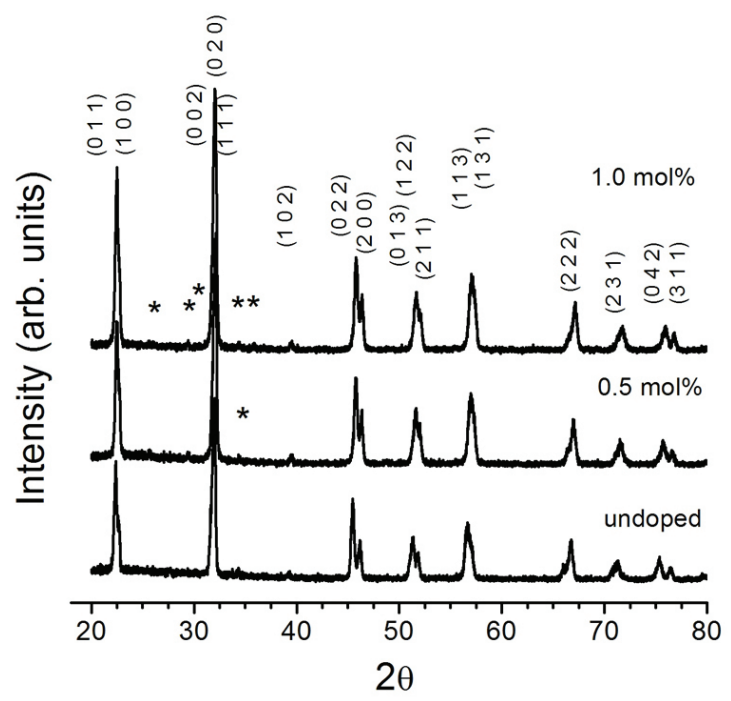

Figure 1. XRD patterns of pure and zinc-doped KNN ceramic. (*) Signals corresponding to $\mathrm{K}_{4} \mathrm{Nb}_{6} \mathrm{O}_{17}$ (JCPDS 76-0977).

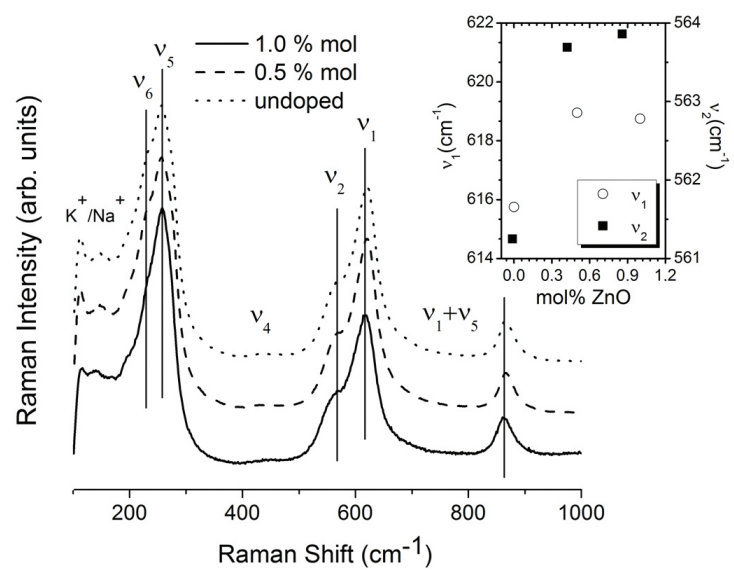

Figure 2. Raman spectra corresponding to pure KNN and KNN doped with several zinc amounts $\left(0.5\right.$ to 1 mol\%). Insert: $v_{1}$ and $v_{2}$ Raman modes obtained after fit Raman spectra as a function of zinc concentration. 
related to the vibrations of the $\mathrm{NbO}_{6}^{-}$octahedron consist of $A_{1 g}\left(v_{1}\right)+\operatorname{Eg}\left(v_{2}\right)+F_{1 u}\left(v_{3}, v_{4}\right)+F_{2 g}\left(v_{5}\right)+F_{2 u}\left(v_{6}\right)$. Vibrations modes $A_{1 g}\left(v_{1}\right)+E_{g}\left(v_{2}\right)+F_{1 u}\left(v_{3}\right)$ are stretching modes, and the rest of them are bending modes. In particular, $A_{1 g}\left(v_{1}\right)$ and $F_{2 g}\left(v_{5}\right)$ have been detected as being relatively strong scatterings in similar systems to the one studied in this work due to a near-perfect equilateral octahedral symmetry. Finally, the peaks in the region between 100 and $160 \mathrm{~cm}^{-1}$ can be associated with translational models of alkaline niobates $\mathrm{K}^{+} / \mathrm{Na}^{+}$and rotational modes of the $\mathrm{NbO}_{6}^{-}$octahedron ${ }^{18,19}$.

The insert of Figure 2 shows the deconvolution of vibration modes $v_{1}$ and $v_{2}$, performed using two Lorentzian functions. It is observed that $v_{1}$ and $v_{2}$ wave numbers move to higher values when $\mathrm{ZnO}$ concentration increases at to $0.5 \mathrm{~mol} \%$. However, when the doping level is increased, $v_{1}$ moves toward low frequency. This change can be related to a decrease in binding strength caused by an increase in the $\mathrm{Nb}-\mathrm{O}$ distance associated with the oxygen vacancies formation ${ }^{20}$. On the other hand, the increasing in $v_{2}$ by the $\mathrm{Zn}$ concentration can be related to modifications in the stabilized perovskite structure.

The increasing in $v_{1}$ suggests that the stiffness of the bond between cations in B-positions and the coordinated oxygen become stronger. This behavior can be related to an enlargement in the tetragonality degree and to the substitution of $\mathrm{Na}^{+}$or $\mathrm{K}^{+}$in A-positions by $\mathrm{Zn}^{2+}$ ions. Comparing with other additives previously studied, such as calcium or barium ${ }^{9}, \mathrm{Zn}^{2+}$ ions replace alkaline elements or niobium ions depending on the doping level.

In Table 1, the values of density and porosity values of $\mathrm{KNN}$ ceramics with different percentages of $\mathrm{ZnO}$ are presented. From this table, the addition of the smallest $\mathrm{Zn}^{2+}$ amount $(0.5 \mathrm{~mol} \%)$ increases the density value, although the highest concentration increases the porosity. This behavior could be attributed to the sintering aid effect of this additive, and the formation of the secondary phase which possesses a lower theoretical density than the perovskite phase ${ }^{21}$.

Figure 3 shows Scanning Electron Microscopy (SEM) images of the sintered samples. The SEM-micrographs show the typical KNN morphology consisting of faceted grains with a bimodal grain size distribution. Undoped samples present cubic grains with an average grain size of $1.61 \pm 1.02 \mu \mathrm{m}$. On the other hand, samples with $0.5 \mathrm{~mol} \%$ of $\mathrm{ZnO}$ present similar grain size, distribution and morphology, although a small increase in the average grain size $(1.65 \pm 0.95 \mu \mathrm{m})$ and the apparition of some glassy phase are observed. Samples with highest $\mathrm{ZnO}$ amount (1 $\mathrm{mol} \%$ ), also present a bimodal grain distribution in which large grains ( $\sim 6$ to $8 \mu \mathrm{m})$ and the small ones $(\sim 0.5$ to $2 \mu \mathrm{m})$ with an average grain size of $1.68 \pm 1.10 \mu \mathrm{m}$. For this reason, it can be observed in the histogram a heterogeneous distribution with a few big grains joint a large amount of small grains, generating an average size similar to undoped ceramics.

According to the phase diagram the niobium excess forms a liquid at $1,058^{\circ} \mathrm{C}$ that could promote sintering with grain coarsening ${ }^{16,20}$. Also, the appearance of the secondary phase is associated with the transitory liquid phase that assisted sintering process. From SEM images, the formation of a liquid phase during the sintering process is responsible for the existence of big grains conformed by other small grains, and of small bonded grains.

Moreover, as the amount of zinc increases, niobium is replaced from the perovskite lattice and, consequently, the transient liquid phase and niobium-rich secondary phases are promoted. From these results, this additive could improve the grain growth due to the liquid phase formation during the sintering process favoring the use of lower sintering temperatures.

Figure 4 shows real permittivity and loss tangent values as a function of frequency for samples with different additive amounts. In all cases, it can be observed that at low frequency, permittivity decreases with frequency due to a space charge relaxation process characteristic of the polycrystalline material. Additionally, a relaxation process at high frequency $(\sim 6 \mathrm{MHz})$ which is associated with a dipolar relaxation phenomenon can be detected. In these samples, the addition of zinc oxide reduces the effect of frequency and increases the real permittivity values at low frequencies, probably due to a better densification of doped ceramics.

Table 1, also shows values of real permittivity ( $\left.\varepsilon^{\prime}\right)$, loss tangent $(\tan \delta)$ and piezoelectric constant $\left(\mathrm{d}_{33}\right)$ corresponding to $\mathrm{KNN}$ with different zinc amounts (0 to $1 \mathrm{~mol} \%)$. From these values, it can be observed that the incorporation of this additive improves the dielectric properties of the device, increasing the real permittivity and decreasing the loss tangent. Moreover, an improvement in the piezoelectric constant value with the lowest percentage of zinc was found. These enhanced properties are associated with the high density values obtained with the $\mathrm{ZnO}$ addition, using the same sintering cycle.

Figure 5 presents the hysteresis loops at room temperature of sintered samples. Pure KNN sample shows a remnant polarization $\left(\mathrm{P}_{\mathrm{r}}\right) 13.8 \mu \mathrm{C} / \mathrm{cm}^{2}$, which is greater than the $\mathrm{Zn}$-doped samples with 8.5 and $5.4 \mu \mathrm{C} / \mathrm{cm}^{2}$ for samples with $0.5 \mathrm{~mol} \%$ and $1 \mathrm{~mol} \%$, respectively. The coercive electric field $\left(E_{c}\right)$, and the saturation polarization values $\left(\mathrm{P}_{\mathrm{s}}\right)$, for the doped samples with 0 to $1 \mathrm{~mol} \%$ of $\mathrm{Zn}^{2+}$, are $17.3,19.0$ and $14 \mathrm{kV} / \mathrm{cm}$ and $18.3,13.3$ and $10.8 \mu \mathrm{C} / \mathrm{cm}^{2}$, respectively.

Table 1. Density and porosity values, and dielectric and piezoelectric properties of the studied samples. Theoretical density $4.51 \mathrm{~g} / \mathrm{cm}^{3[5]}$.

\begin{tabular}{lccccc}
\hline \multicolumn{1}{c}{ Sample } & $\begin{array}{c}\text { Density } \\
\left(\mathbf{g} / \mathbf{c m}^{\mathbf{3}}\right)\end{array}$ & $\begin{array}{c}\text { Porosity } \\
(\mathbf{\%})\end{array}$ & $\begin{array}{c}\varepsilon^{\prime} \\
(\mathbf{1 0 k H z})\end{array}$ & $\begin{array}{c}\tan \delta \\
(\mathbf{1 0 k H z})\end{array}$ & $\mathbf{d}_{\mathbf{3 3}}$ \\
\hline KNN pure & $4.3 \pm 0.9$ & $5.8 \pm 2.5$ & 352 & 0.13 & 86 \\
KNN 0.5\%mol ZnO & $4.4 \pm 0.1$ & $3.3 \pm 1.0$ & 359 & 0.13 & 95 \\
KNN1.0\%mol ZnO & $4.3 \pm 0.1$ & $5.8 \pm 0.7$ & 408 & 0.10 & 90 \\
\hline
\end{tabular}



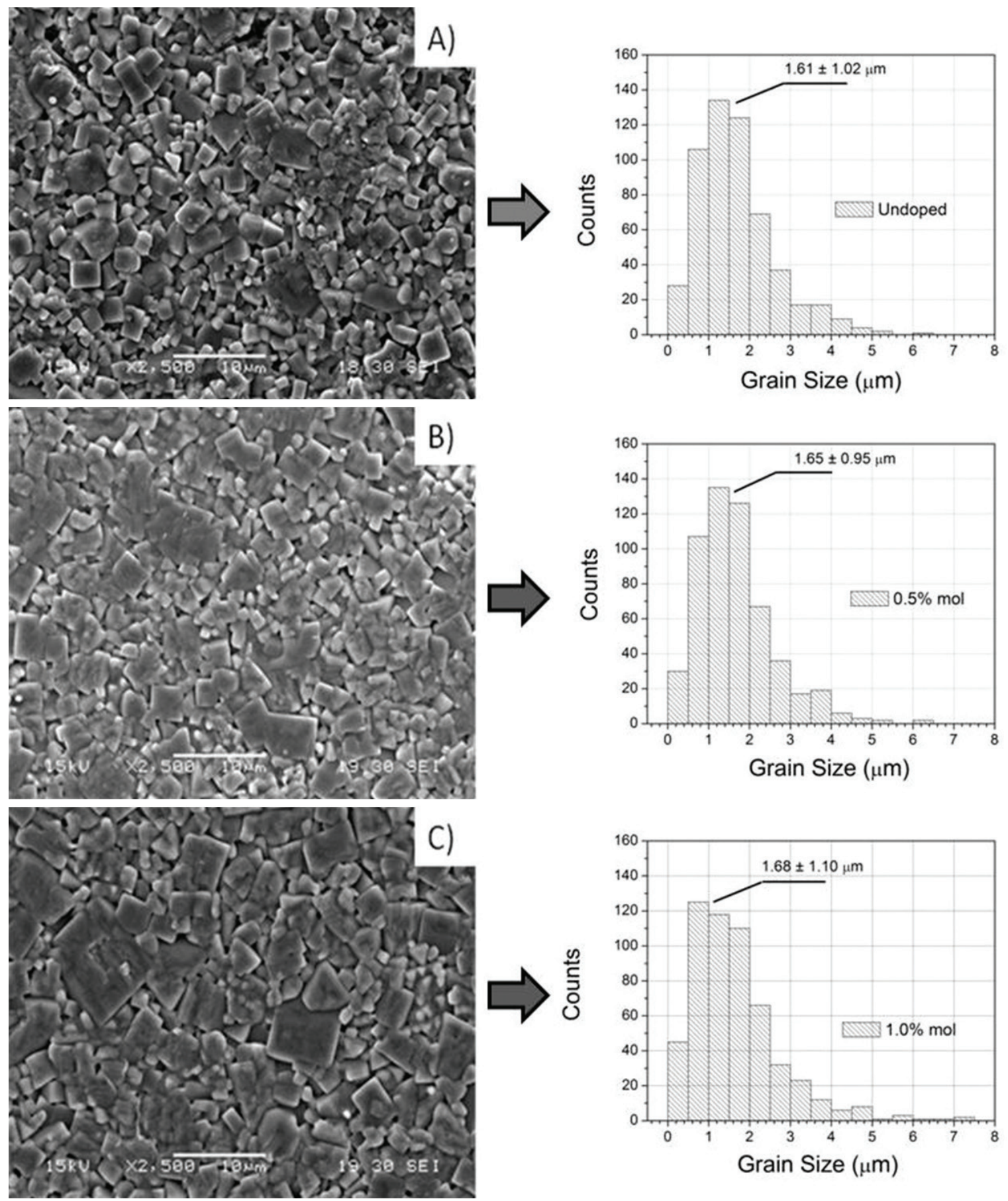

Figure 3. SEM images of pure KNN (A) and KNN doped with several zinc amounts $0.5 \mathrm{~mol} \%(\mathrm{~B})$, and $1 \mathrm{~mol} \%$ (C).

From the decrease in the coercive electric field value, a softening effect on the ferroelectric properties of KNN with zinc addition is detected. This result cannot be related to the possible $\mathrm{Zn}^{2+}$ substitution in $\mathrm{Nb}^{5+}$ positions of the lattice with the consequent oxygen vacancy generation, which produces a hardening effect on the ferroelectric properties of the material. Then, the small decrease of $\mathrm{E}_{c}$ can be attributed to a decrease of the oxygen vacancies amount due to $\mathrm{Zn}^{2+}$ donor ions (A-site replacement) that pinned the domain wall motion. Moreover, the increasing in the grain size reduces the anchoring effect of grain boundaries which limit the material polarization and decrease the coercive field of the samples and the energy involved to change the polarization of the material. Hayati et al. found that nano- $\mathrm{ZnO}$ additive increased the grain size of the KNN ceramics considerably and, larger grains lead to lower coercive fields ${ }^{12}$. The larger 


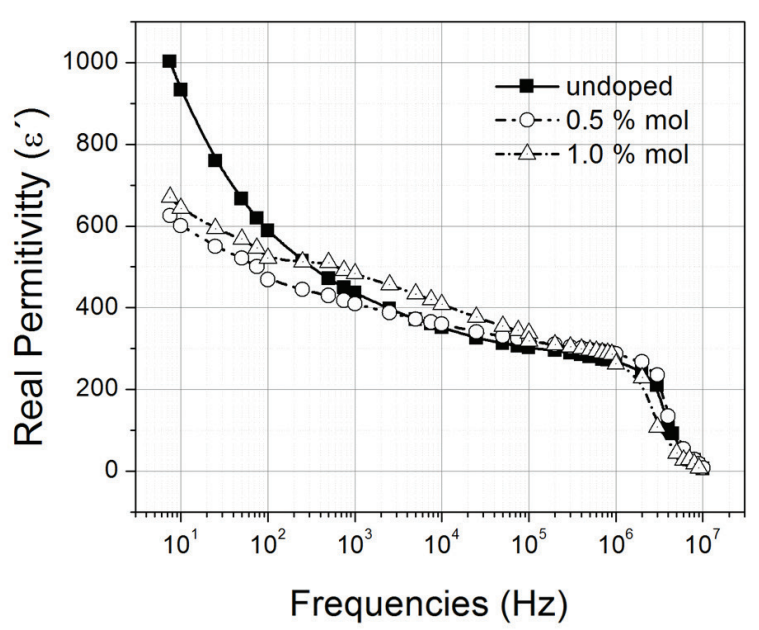

(a)

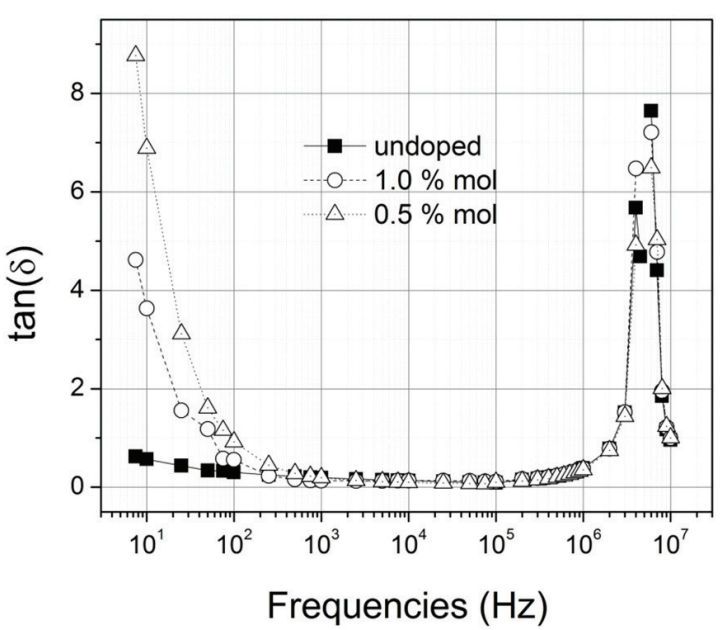

(b)

Figure 4. Curves of real permittivity (a) and loss tangent (b) as a function of frequency at room temperature.

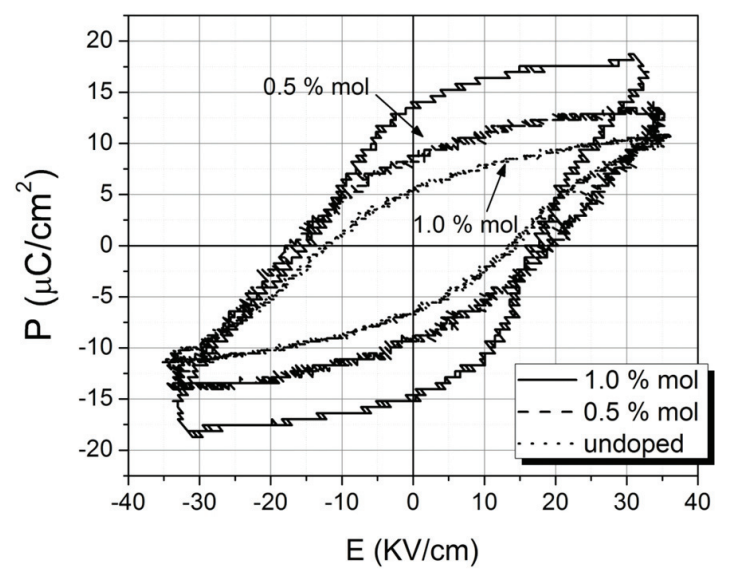

Figure 5. Hysteresis loops of sintered samples. Measuring conditions: room temperature, ac field, electric field of $35 \mathrm{kV} / \mathrm{cm}$ and frequency of $50 \mathrm{~Hz}$.

the grains gives the larger the domain size and smaller the domain wall width. Decreasing the domain wall width facilitates the domain wall switching which results to lower coercive fields. Furthermore, with the highest doping level $\mathrm{Zn}^{2+}$ ions enter in B-positions. It is known, that when $\mathrm{Zn}^{2+}$ ions substitute in $\mathrm{B}$ positions $\left(\mathrm{Nb}^{5+}\right.$ ion sites) in perovskite structure, which results in the formation of oxygen vacancies that makes the ceramic hard, a higher coercive field than pure $\mathrm{KNN}$ is expected ${ }^{14}$. According to these results, coercive electric field and saturation polarization values were strongly dependent on structural and microstructural modifications produced by this additive.

\section{Conclusions}

In this study, the microstructure, crystalline phases, and electrical properties of $\mathrm{ZnO}$-doped $\mathrm{KNN}$ ceramics were investigated. For $\mathrm{ZnO}$-doped samples, a secondary phase was observed by XRD, accompanied by an increase in the grain size. At the lowest doping level used in this work $(0.5 \mathrm{~mol} \%)$, density and piezoelectric properties were improved. A shift in the $A_{1 g}$ vibration mode $\left(v_{1}\right)$ to higher wave numbers related to the $\mathrm{Zn}^{2+}$ substitution in A-positions of the perovskite structure was observed. This variation was associated with an increasing in the tetragonal phase. This result produced an electric softening of the material properties, which was evidenced by an increase in the piezoelectric properties. The diminution in the density value with the highest doping level was attributed to the alkali elements volatilization. Furthermore, from Raman spectroscopy the substitution of niobium ions by zinc ions was observed.

Finally, considering that $\mathrm{Zn}^{2+}$ ions replace alkaline elements in A-positions of the perovskite lattice, the incorporation of this additive at the initial stage of the $\mathrm{K}_{0.5} \mathrm{Na}_{0.5} \mathrm{NbO}_{3}$ synthesis would increase the A-site replacement and hence the loss of the alkali elements (mainly sodium).

\section{Acknowledgements}

This work was supported by Consejo Nacional de Investigaciones Científicas y Técnicas (CONICET), Agencia Nacional de Promoción Científica y Tecnológica (ANPCyT) and Universidad Nacional de Mar del Plata (UNMdP), Argentina. In addition, L'Oréal - UNESCO “For Women in Science" Program is acknowledged. 


\section{References}

1. Saito Y, Takao H, Tani T, Nonoyama T, Takatori K, Homma $\mathrm{T}$ et al. Lead-free piezoceramics. Nature. 2004; 432:84-87. http://dx.doi.org/10.1038/nature03028

2. Alkoy EM and Papila M. Microstructural features and electrical properties of copper oxide added potassium sodium niobate ceramics. Ceramics International. 2010; 36(6):1921-1927. http://dx.doi.org/10.1016/j.ceramint.2010.03.018

3. Dai Y-J, Zhang X-W and Chen K-P. Morphotropic phase boundary and electrical properties of $\mathrm{K}_{1-\mathrm{x}} \mathrm{Na}_{\mathrm{x}} \mathrm{NbO}_{3}$ lead-free ceramics. Applied Physics Letters. 2009; 94:042905. http:// dx.doi.org/10.1063/1.3076105

4. Jaffe B, Cook WR Jr and Jaffe H. Piezoelectric ceramics. New York: Academic Press; 1971.

5. Malic B, Bernard J, Bencan A and Kosec M. Influence of zirconia addition on the microstructure of $\mathrm{K}_{0.5} \mathrm{Na}_{0.5} \mathrm{NbO}_{3}$ ceramics. Journal of the European Ceramic Society. 2008; 28:1191-1196. http://dx.doi.org/10.1016/j.jeurceramsoc.2007.11.004

6. Shrout TR and Zhang S. Lead-free piezoelectric ceramics: Alternatives for PZT? Journal of Electroceramics. 2007; 19:113126. http://dx.doi.org/10.1007/s10832-007-9047-0

7. Ramajo L, Parra R, Ramírez MA andCastro MS. Electrical and microstructural properties of $\mathrm{CaTiO}_{3}$-doped $\mathrm{K}_{1 / 2} \mathrm{Na}_{1 / 2} \mathrm{NbO}_{3}$-lead free ceramics. Bulletin of Materials Science. 2011;34(6):12131217. http://dx.doi.org/10.1007/s12034-011-0241-y

8. Zhang S, Xia R, Shrout T, Zang G and Wang J. Influence of $\mathrm{Ni}$ doping on the properties of perovskite molybdates $\mathrm{SrMo}_{1-\mathrm{x}} \mathrm{Ni}_{\mathrm{x}} \mathrm{O}_{3}$ $(0.02 \leq \mathrm{x} \leq 0.08)$. Solid State Commun. 2007; 141:675- 675 . http://dx.doi.org/10.1016/j.ssc.2007.01.007

9. Taub J, Ramajo L and Castro MS. Phase structure and piezoelectric properties of Ca- and Ba-doped $\mathrm{K}_{1 / 2} \mathrm{Na}_{1 / 2} \mathrm{NbO}_{3}$ lead-free ceramics. Ceramics International. 2013; 39(4):35553561. http://dx.doi.org/10.1016/j.ceramint.2012.10.181

10. Kang IY, Seo IT, Cha YJ, Choi JH, Nahm S, Sung TH et al. Low temperature sintering of $\mathrm{ZnO}$ and $\mathrm{MnO}_{2}$-added $\left(\mathrm{Na}_{0.5} \mathrm{~K}_{0.5}\right) \mathrm{NbO}_{3}$ ceramics. Journal of the European Ceramic Society. 2012; 32(10):2381-2387. http://dx.doi.org/10.1016/j. jeurceramsoc.2012.01.030

11. Ramajo L, Castro M, Rubio-Marcos F and Fernandez-Lozano J. Influence of $\mathrm{MoO}_{3}$ on electrical and microstructural properties of $\left(\mathrm{K}_{0.44} \mathrm{Na}_{0.52} \mathrm{Li}_{0.04}\right)\left(\mathrm{Nb}_{0.86} \mathrm{Ta}_{0.10} \mathrm{Sb}_{0.04}\right) \mathrm{O}_{3}$. Journal of Materials Science: Materials in Electronics. 2013; 24(9):3587-3593. http://dx.doi.org/10.1007/s10854-013-1289-9

12. Hayati R and Barzegar A. Microstructure and electrical properties of lead free potassium sodium niobate piezoceramics with nano $\mathrm{ZnO}$ additive. Materials Science and Engineering
B. 2010; 172(2):121-126. http://dx.doi.org/10.1016/j. mseb.2010.04.033

13. Rubio Marcos F, Romero JJ, Navarro Rojero MG and Fernandez JF. Effect of $\mathrm{ZnO}$ on the structure, microstructure and electrical properties of $\mathrm{KNN}$-modified piezoceramics. Journal of the European Ceramic Society. 2009; 29(14):30453052. http://dx.doi.org/10.1016/j.jeurceramsoc.2009.04.026

14. Li HT, Zhang BP, Cui M, Yang WG, Ma N and Li JF. Microstructure, crystalline phase, and electrical properties of $\mathrm{ZnO}$-added $\mathrm{Li}_{0.06}\left(\mathrm{Na}_{0.535} \mathrm{~K}_{0.48}\right)_{0.94} \mathrm{NbO}_{3}$ ceramics. Current Applied Physics. 2011; 11(3):S184-S188. http://dx.doi. org/10.1016/j.cap.2010.12.026

15. Klein N, Hollenstein E, Damjanovic D, Trodahl HJ, Setter N and Kuball M. A study of the phase diagram of $(\mathrm{K}, \mathrm{Na}, \mathrm{Li}) \mathrm{NbO}_{3}$ determined by dielectric and piezoelectric measurements, and Raman spectroscopy. Journal of Applied Physics. 2007; 102:014112. http://dx.doi. org/10.1063/1.2752799

16. Ramajo L, Taub J and Castro MS. Influence of zirconium addition on final properties of $\mathrm{K}_{0.5} \mathrm{Na}_{0.5} \mathrm{NbO}_{3}$-based ceramics. Journal of Materials Science: Materials in Electronics. 2014; 25(1):168173. http://dx.doi.org/10.1007/s10854-013-1568-5

17. Rubio-Marcos F, Marchet P, Merle-Méjean T and Fernandez JF Role of sintering time, crystalline phases and symmetry in the piezoelectric properties of lead-free KNN-modified ceramics. Materials Chemistry and Physics. 2010; 123(1):91-97. http:// dx.doi.org/10.1016/j.matchemphys.2010.03.065

18. Rubio-Marcos F, Navarro-Rojero MG, Romero JJ, Marchet $\mathrm{P}$ and Fernández JF. Piezoceramics properties as a function of the structure in the system $(\mathrm{K}, \mathrm{Na}, \mathrm{Li})(\mathrm{Nb}, \mathrm{Ta}, \mathrm{Sb}) \mathrm{O}_{3}$. IEEE Transactions on Ultrasonics, Ferroelectrics, and Frequency Control. 2009; 56(9):1835-1842. http://dx.doi.org/10.1109/ TUFFC.2009.1258

19. Rubio-Marcos F, Marchet P, Romero JJ and Fernández JF. Structural, microstructural and electrical properties evolution of $(\mathrm{K}, \mathrm{Na}, \mathrm{Li})(\mathrm{Nb}, \mathrm{Ta}, \mathrm{Sb}) \mathrm{O}_{3}$ lead-free piezoceramics through $\mathrm{NiO}$ doping. Journal of the European Ceramic Society. 2011; 31(13):2309-2317. http://dx.doi.org/10.1016/j. jeurceramsoc.2011.05.041

20. Fisher JG, Rout D, Moon KS and Kang JK. Structural changes in potassium sodium niobate ceramics sintered in different atmospheres. Journal of Alloys and Compounds. 2009; 479:467472. http://dx.doi.org/10.1016/j.jallcom.2008.12.100

21. Yang W, Jin D, Wang T and Cheng J. Effect of oxide dopants on the structure and electrical properties of $\left(\mathrm{Na}_{0.5} \mathrm{~K}_{0.5}\right) \mathrm{NbO}_{3}$ $\mathrm{LiSbO}_{3}$ lead-free piezoelectric ceramics. Physica B: Physics of Condensed Matter. 2010; 405(7):1918-1921. http://dx.doi. org/10.1016/j.physb.2010.01.074 